\title{
Entertaining Education - Using Games-Based and Service-Oriented Learning to Improve STEM Education
}

\author{
Jon Preston and Briana Morrison \\ Southern Polytechnic State University, 1100 S Marietta Parkway \\ Marietta, GA 30060 USA \\ \{jpreston, bmorriso\} @spsu .edu
}

\begin{abstract}
This paper addresses the development of a computer game design and development curriculum at the authors' institution. The basis for curriculum decisions, as well as comparison to the other institutions' curricula is covered. In situating the curriculum within the current degree programs, games-based versions of existing courses are also being offered. The experience of the authors with the initial offering of a games-based introductory programming course is also explained, along with the initial assessment of results from the experience. Our experience of using games-based learning in an introductory laboratory is presented. Finally, we demonstrate how games-based learning can be extended beyond the classroom as we work to promote science, technology, engineering, and mathematics (STEM) with local elementary schools; our current project develops an ocean ecosystem exploration game that teaches oceanography and ecological sustainability.
\end{abstract}

Keywords: curriculum, games-based, learning, programming, motivation, STEM, K12, development, sustainability.

\section{Summary}

This paper presents our encompassing vision of incorporating gaming at our institution. Games-based learning offers an opportunity to motivate students in existing disciplines as well as expand the educational opportunities within universities. It has been exciting to see how motivated students at our university have been with the addition of gaming education at our institution. The degree program has received very favorable reviews from students and has generated interest from perspective students. The gaming based versions of the software development courses have proven so popular that additional sections have had to be added to the course schedule. The community that our play and development group of students has developed is also impressive, and it is inspiring to see our university students making connections with and motivating the elementary students. In an era where student interest in STEM education seems to be waning, we hope that we have had a long-term impact on students to see that science, mathematics, and computer science are all interesting fields where creativity and imagination are key elements of success. 